\title{
Hubungan Intensitas Penggunaan Teknologi Informasi dan Komunikasi dengan Keterlibatan Belajar Mahasiswa Generasi Z
}

\author{
Tejarukmi Mutiara, Dianti E. Kusumawardhani \\ Universitas Indonesia
}

\section{Edcomtech}

Jurnal Kajian

Teknologi Pendidikan

Volume 5, No 1, April 2020

192-201

Submitted 26-05-2020

Accepted 15-06-2020

Corresponding Author

Tejarukmi Mutiara

tejarukmimutiara@gmail.com

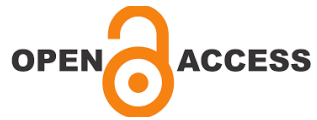

\begin{abstract}
Abstrak
Penelitian ini bertujuan untuk menelaah hubungan antara intensitas penggunaan teknologi informasi dan komunikasi dalam dunia pendidikan terhadap keterlibatan belajar mahasiswa generasi Z. Metode yang digunakan adalah pengisian kuesioner mengenai keterlibatan belajar oleh mahasiswa generasi Z ( $n=108)$. Diperoleh hasil bahwa jangka waktu pertama kali mengenal dan durasi penggunaan teknologi informasi dan komunikasi berkorelasi negatif dengan keterlibatan belajar mahasiswa. Sedangkan, penggunaan teknologi informasi dan komunikasi yang bertujuan untuk kepentingan akademis berkorelasi positif terhadap keterlibatan belajar siswa. Mahasiswa generasi Z sebaiknya mampu meregulasi diri untuk dapat memanfaatkan teknologi informasi dan komunikasi untuk tujuan akademis.
\end{abstract}

Kata Kunci: teknologi informasi dan komunikasi; mahasiswa; generasi Z; keterlibatan belajar.

\begin{abstract}
This study aims to examine the relationship between the intensity of the use of information and communication technology in education to the learning engagement of Generation $Z$ students. The method used is filling out a questionnaire regarding learning involvement by Generation $Z$ students ( $n$ $=108$ ). The result shows that the time period for the first time to recognize and the duration of the use of information and communication technology is negatively correlated with student learning engagement. Meanwhile, the use of information and communication technology aimed at academic interests is positively correlated to student learning engagement. Generation Z students should be able to regulate themselves to be able to utilize information and communication technology for academic purposes.
\end{abstract}

Keywords: information and communications technology; university students; generation Z; student engagement. 


\section{PENDAHULUAN}

Teknologi informasi dan komunikasi (TIK) telah menjadi bagian hidup masyarakat Indonesia dalam satu dekade belakangan ini. Ranah pendidikan pun turut memanfaatkan penggunaan TIK dalam proses pembelajaran. Untuk dapat memahami mengenai hubungan dari penggunaan teknologi informasi dan komunikasi dalam lingkungan pendidikan, keterlibatan belajar siswa dalam proses pembelajaran adalah hal yang sangat penting karena berfungsi sebagai jalur perilaku dimana proses motivasi siswa berkontribusi pada pembelajaran dan perkembangan mereka (Dogan, 2015). Sebagai contoh, beberapa penelitian telah mengkonfirmasi bahwa keterlibatan belajar memprediksi prestasi akademik siswa (Hughes, 2015) dan penyelesaian jenjang pendidikan (Voelkl, 2012 dalam Christenson, 2013). Keterlibatan juga menjadi penting karena pengajar bergantung pada hal ini sebagai indikator motivasi siswa yang dapat diobservasi selama pembelajaran (Saeed \& Zyngier, 2012).

Pemanfaatan TIK ini dalam dunia pendidikan memberikan dampak dalam proses belajar mengajar yang dialami oleh pembelajar. Penggunaan TIK yang muncul dalam lingkungan pendidikan misalnya sebagai sarana untuk memperoleh dan berbagi informasi sampai untuk interaksi dengan teman sebaya maupun pendidik di institusi, dapat dimaklumi jika pembelajar menggunakan berbagai teknologi untuk memfasilitasi dan menambah pengalaman belajar dan untuk mencapai tuntutan akademis dengan efektif (Cole, 2019).

Berbagai hasil penelitian muncul: di satu sisi teknologi digital memang betul menambah dan sebenarnya telah mengubah pengajaran dan pembelajaran di pendidikan tinggi (Beetham \& Sharpe, 2013), di sisi lain teknologi juga dianggap sebagai disrupsi, sehingga universitas perlu mempersiapkan berbagai dampak yang akan muncul karenanya (Losh, 2014).

Keterlibatan belajar adalah konstruksi yang mendapat banyak perhatian dari para peneliti dan sampai saat ini belum dapat dipahami dengan jelas. Pada beberapa penelitian, pemanfaatan TIK memiliki hubungan yang positif dengan keterlibatan belajar terutama dalam hal motivasi dan prestasi akademis siswa (Fonseca, Marti, Redondo, Navarro dan Sanchez, 2014, Suhail dan Barges, 2006)), indeks prestasi kumulatif (Gulek dan Demirtas, 2005), minat belajar dan partisipasi (Trimmel dan Bachmann, 2004; Drain, Grier dan Sun, 2012). Namun, terdapat pula penelitian-penelitian yang menemukan bahwa penggunaan TIK dalam pendidikan memiliki efek negatif terhadap prestasi akademik (Derbyshire et al., 2013; Jacobsen dan Forste, 2011; Sana, Weston dan Cepeda, 2013), mengganggu kegiatan lain terutama istirahat (Anderson et al., 2012) dan menyebabkan ketergantungan atau adiksi yang kemudian berdampak menjadi gangguan perilaku (Awan dan Khan, 2016).

Di Indonesia sendiri, survei Asosiasi Penyelenggara Jasa Internet Indonesia (APJII) mengenai penetrasi dan profil perilaku pengguna internet Indonesia pada tahun 2018 menemukan data bahwa mayoritas pengguna teknologi informasi dan komunikasi adalah remaja yang berusia 15-19 tahun yaitu generasi $Z$ dalam penelitian ini dan mayoritas dari mereka tidak menggunakan TIK untuk kepentingan akademis melainkan untuk mengirimkan pesan dan mengakses sosial media.

Dalam institusi pendidikan di Indonesia, usia aktif belajar adalah siswa yang berusia 7 tahun sampai dengan usia 23 tahun. Mereka adalah yang termasuk dalam generasi Z menurut teori generasi. Generasi Z adalah mereka yang lahir pada tahun 1995 - 2012 (MacKenzie \& McGuire, 2016; Wiedmer, 2015), sehingga mereka kini adalah yang berusia 7 - 28 tahun. Lahir di era teknologi, kebanyakan generasi $Z$ sangat mengenal internet dan sosial media karena mereka diperkenalkan oleh orang tuanya sejak mereka kecil. Bagi generasi Z, internet adalah oksigen, mereka tidak dapat membayangkan bagaimana bisa hidup tanpa internet (Oblinger \& Oblinger, 2005).

Di Indonesia sendiri, generasi $Z$ adalah populasi terbesar berdasarkan data Badan Pusat Statistik di tahun 2018. Selain itu, pada tahun 2030 juga diprediksikan bahwa Indonesia akan mengalami bonus demografi, yaitu dimana 
usia produktif akan jauh lebih banyak dengan usia non produktif. Jika bonus demografi ini tidak ditanggapi dengan serius, maka bonus demografi akan membawa keterpurukan dalam berbagai aspek kehidupan bangsa Indonesia, terutama perekonomian. Perlu diperhatikan bahwa mereka yang akan menjadi usia produktif di tahun 2030 nanti, adalah mereka yang termasuk dalam generasi $Z$ pada tahun 2019 ini.

Pendidikan tinggi yaitu pendidikan ditingkat universitas adalah institusi pendidikan yang telah mulaimengoptimalkan TIK dalam lingkup pembelajarannya. Oleh karena itu, penelitian ini akan lebih fokus pada pembelajar yang berusia 18-24 tahun, yaitu para mahasiswa yang sedang berada pada bangku perkuliahan jenjang S1. Dengan penggunaan teknologi dan internet yang tidak lagi dapat dipisahkan dari kehidupan mahasiswa dan berbagai penelitian sebelumnya yang memberikan hasil yang berbeda dan kontradiktif, penelitian ini bertujuan untuk memperoleh data lebih lanjut mengenai penggunaan teknologi dan internet di mahasiswa yang merupakan generasi $\mathrm{Z}$ di Indonesia dan bagaimana hubungannya terhadap keterlibatan mahasiswa dalam perkuliahan. Peneliti akan mengumpulkan data mengenai intensitas penggunaan teknologi informasi dan komunikasi mahasiswa dan bagaimana hubungan serta hubungannya terhadap keterlibatan belajar siswa pada mahasiswa tingkat 1 dan 2 program studi S1 Fakultas Psikologi Universitas $\mathrm{X}$.

\section{Generasi Z}

Francis \& Hoefel (2018) dalam artikel yang dilansir dari website perusahaan McKinsey membagi generasi berdasarkan tahun kehidupan menjadi empat generasi, antara lain baby boomer yaitu generasi yang lahir pada tahun 1940-1959, generasi X yaitu generasi yang lahir pada tahun 1960-1979, generasi $Y$ yang lahir pada tahun 19801994, dan generasi $Z$ yaitu generasi yang lahir dari tahun 1995-2012. Mereka adalah generasi pertama yang secara menyeluruh dan langsung terekspos dengan teknologi digital seperti situs jejaring dan informasi berlebih di internet (Turner, 2015). Serupa dengan generasi sebelumnya, perkembangan karakteristik perilaku generasi Z banyak sekali dipengaruhi oleh lingkungan yang berbagai macam dan komponen yang ada di sekitarnya. Generasi ini tumbuh dengan media yang sangat canggih beserta lingkungan teknologi yang telah membuat mereka menjadi generasi yang paham teknologi dan lebih ahli dibandingkan generasi yang membesarkan mereka, yaitu generasi $X$.

Generasi $Z$ yang menjadi fokus dalam penelitian ini adalah mahasiswa yang berusia 18-24 tahun, yang mana merupakan mahasiswa jenjang S1 di perguruan tinggi. Hal ini menjadi pertimbangan peneliti dikarenakan untuk konteks pendidikan Indonesia sendiri, pemanfaatan teknologi informasi dan komunikasi belum banyak dioptimalkan di jenjang pendidikan sebelum pendidikan tinggi. Sedangkan, di perguruan tinggi, berdasarkan survei awal yang dilakukan peneliti, para mahasiswa telah menggunakan teknologi informasi komunikasi seperti laptop, ipad, smartphone sebagai media belajar mereka.

\section{Intensitas Penggunaan Teknologi Informasi dan Komunikasi dan Keterlibatan belajar siswa}

Intensitas penggunaan TIK dalam keseharian pembelajar, dalam hal ini mahasiswa, menjadi menarik diteliti karena beberapa alasan antara lain: mahasiswa pada usianya sekarang adalah termasuk dalam generasi $\mathbf{Z}$ yang sejak lahir telah terpapar dengan keberadaan dan pemanfaatan TIK dalam kehidupan sehari-hari mulai dari orang tua atau pengasuhnya sendiri. Selain itu, dalam dunia pendidikan tinggi di universitas, mahasiswa telah terbiasa menggunakan TIK sebagai salah satu media dan sumber pembelajaran. Berdasarkan survei awal yang dilakukan oleh peneliti pada November 2019, para mahasiswa yang termasuk usia generasi $Z$ ini memanfaatkan berbagai situs dan jejaring sosial sebagai sumber materi belajar dan untuk memperoleh pemahaman lebih baik dari materi yang telah diajarkan di kelas. Beberapa situs favorit yang sering mereka kunjungi antara lain: Medium, Youtube dan Google Scholar. 
Keterlibatan belajar siswa telah menjadi fokus perhatian penelitian-penelitian dalam beberapa tahun terakhir. Menurut Fredricks et al. (2004) keterlibatan belajar siswa adalah wujud dari motivasi yang tampak melalui tindakan yaitu perilaku, emosi, dan kognitif yang ditampilkan oleh siswa dalam kegiatan akademik. Maka keterlibatan belajar terdiri dari tiga dimensi, yaitu keterlibatan perilaku (behavioral engagement), keterlibatan emosional (emotional engagement) dan keterlibatan kognitif (cognitive engagement). Ketiga dimensi ini dioperasionalisasikan dalam pernyataan perilaku yang dialami oleh individu.

Keterlibatan perilaku adalah tindakan yang positif seperti mematuhi norma, mengikuti peraturan kelas, dan tidak pernah berperilaku buruk seperti bolos sekolah atau terlibat masalah (Fredricks, 2013).

Sedangkan keterlibatan emosional berfokus pada keberadaan perasaan dan reaksi positif atau negatif terhadap guru, teman sekelas, dan pegawai sekolah. Selain itu, pengidentifikasian diri juga termasuk di dalamnya, seperti kepemilikan, atau perasaan dianggap penting bagi sekolah dan perasaan sukses terkait dengan prestasi sekolah (Fredricks, 2013).

Keterlibatan kognitif adalah bersikap tekun, strategis, dan keinginan untuk memunculkan usaha optimal untuk memahami gagasan yang kompleks atau menguasai keterampilan-keterampilan yang sulit (Fredricks et al., 2004).

Dalam penelitian ini, intensitas dioperasionalisasikan dalam jangka waktu pertama kali mengenal TIK, durasi penggunaan TIK dalam satu hari dan persentase banyak penggunaan TIK untuk kepentingan akademis, kemudian peneliti mengembangkan beberapa pertanyaan penelitian yang ditujukan untuk mahasiswa Fakultas Psikologi Universitas $\mathrm{X}$ usia 18-24 tahun, antara lain:

Pertanyaan 1: Apakah terdapat hubungan antara jangka waktu pertama kali mengenal TIK dengan keterlibatan belajar?

Pertanyaan 2: Apakah terdapat hubungan antara durasi penggunaan TIK dalam satu hari dengan keterlibatan belajar?

Pertanyaan 3: Apakah terdapat hubungan antara persentase menggunakan TIK untuk kepentingan akademis dengan keterlibatan belajar?

\section{METODE}

Penelitian ini adalah penelitian korelasional dengan partisipan penelitian adalah 108 mahasiswa jenjang S1, Fakultas Psikologi, Universitas $\mathrm{X}$, berusia rata-rata 19 tahun dan dipilih dengan metode convenience sampling. Diantaranya adalah $19,4 \%$ laki-laki dan $80,6 \%$ perempuan. Usia berkisar dari 18 sampai dengan 20 tahun ( $M=19$ tahun, SD $=0.5$ ). Pengumpulan data dilakukan setelah responden mengisi formulir kesediaan berpartisipasi dalam penelitian. Responden juga diinformasikan bahwa nama yang dituliskan hanya berupa inisial serta semua data yang diberikan hanya diperuntukkan untuk kepentingan penelitian.

Instrumen yang digunakan dalam penelitian ini antara lain keterlibatan belajar yang diukur dengan menggunakan Schools Questionnaire-Engagement Composite (SESQENG) yang dikembangkan oleh Hart, Stewart, dan Jimerson (2011) dan diadaptasikan oleh peneliti dengan melakukan uji tes keterbacaan dan studi pilot ke beberapa calon responden. SESQ-ENG disusun dari tiga dimensi pembentuknya yaitu keterlibatan perilaku, keterlibatan emosional, keterlibatan kognitif. Alat ukur keterlibatan belajar siswa ini terdiri dari 33 item yang diisikan dengan self-report oleh responden. Respons yang diperoleh terdiri dari 5 skala poin yang memiliki rentang 1 (Tidak pernah) sampai 5 (Selalu) yang menunjukkan keadaan responden dalam menjawab setiap item yang tersedia.

Pada studi yang dilakukan Hart, Stewart dan Jimerson (2011) diperoleh nilai reliabilitas konsistensi internal dengan Cronbach's Alpha $=.70$. Beberapa literatur menyebutkan bahwa rentang nilai alpha yang dapat diterima adalah $.60 \leq a \leq .90$ (Gliner \& Morgan, 2000). Setelah diadaptasi, diperoleh nilai Cronbach's Alpha = .87. Selain itu dilakukan juga uji validitas dan diperoleh dua item yang tidak valid yaitu item 7 dan 15, sehingga kedua item tersebut tidak diperhitungkan dalam proses analisis data. Dari proses ini, kemudian alat ukur SESQ-ENG yang telah diadaptasikan oleh peneliti dapat 
digunakan untuk penelitian.

Intensitas penggunaan internet diukur dengan meminta responden mengisikan secara nominal jangka waktu pertama kali mereka mengenal TIK, durasi penggunaan TIK dalam satu hari dan persentase sebanyak apa mereka menggunakan TIK untuk kepentingan akademis.

Selanjutnya, analisis data dilakukan dengan uji korelasi untuk mengetahui hubungan variabel bebas yaitu intensitas penggunaan TIK terhadap variabel yang diukur yaitu keterlibatan belajar dengan menggunakan perangkat lunak IBM SPSS Statistics 25 .

\section{HASIL DAN PEMBAHASAN}

Setelah dilakukan pengambilan data, kemudian dilakukan pengolahan data dan diperoleh 108 responden yang berusia 1824 tahun $(M=19 ; S D=0.5)$ dari Fakultas Psikologi, Universitas X. Responden terdiri dari $19.4 \%$ laki-laki dan $80.6 \%$ perempuan.

\section{Tabel 1. Tabel deskripsi hasil analisis data}

\begin{tabular}{|c|c|c|}
\hline & Mean & SD \\
\hline Usia & 19.15 & 0.5 \\
\hline $\begin{array}{l}\text { Jangka waktu pertama kali } \\
\text { mengenal teknologi informasi } \\
\text { dan komunikasi }\end{array}$ & 9.8 & 2.08 \\
\hline $\begin{array}{l}\text { Durasi penggunaan teknologi } \\
\text { informasi dan komunikasi } \\
\text { dalam satu hari }\end{array}$ & 6.9 & 3.4 \\
\hline $\begin{array}{l}\text { Persentase penggunaan } \\
\text { teknologi informasi dan } \\
\text { komunikasi untuk keperluan } \\
\text { akademis }\end{array}$ & 48.98 & 16.5 \\
\hline Emotional engagement & 32.47 & 4.04 \\
\hline Behavioral engagement & 41.71 & 4.84 \\
\hline Cognitive engagement & 45.25 & 5.23 \\
\hline Keterlibatan belajar siswa & 115.26 & 10,78 \\
\hline
\end{tabular}

Dari ketiga indikator intensitas penggunaan TIK pada mahasiswa Fakultas Psikologi, Universitas $\mathrm{X}$ ditemukan bahwa rata-rata jangka waktu pertama kali mereka menggunakan TIK adalah 9 tahun ( $M=9.8$; SD $=2.08$ ). Dari data durasi penggunaan TIK dalam satu hari diperoleh rata-rata dari responden menggunakan selama 7 jam dalam sehari $(\mathrm{M}=6.9 ; \mathrm{SD}=3.4)$. Kemudian, berdasarkan data yang diperoleh, rata-rata persentase penggunaan TIK untuk kepentingan akademis adalah 49\% ( $M=48.98 ; S D=16.5)$. Dari tiga dimensi keterlibatan belajar siswa diperoleh bahwa rata-rata dimensi keterlibatan emosional paling rendah dimiliki oleh responden yaitu sebesar $32.47(S D=4.04)$, lalu keterlibatan perilaku yaitu $41.71(S D=4.84)$ dan yang paling tinggi adalah keterlibatan kognitif sebesar 45.24. (SD = 5.23).

Berdasarkan hasil uji Pearson Correlation di Tabel 2, ketiga indikator intensi penggunaan TIK memiliki korelasi yang signifikan terhadap keterlibatan belajar siswa. Dua indikator, yaitu jangka waktu pertama kali mengenal TIK dan durasi penggunaan TIK dalam satu hari berkorelasi negatif terhadap keterlibatan belajar siswa pada mahasiswa Fakultas Psikologi, Universitas X. Durasi penggunaan TIK dalam satu hari menunjukkan korelasi negatif yang lebih tinggi yaitu -.126 dan jangka waktu telah mengenal TIK pertama kali menunjukkan nilai -.109. Sedangkan, persentase penggunaan TIK untuk kepentingan akademis memiliki korelasi yang signifikan dan positif terhadap keterlibatan belajar siswa yaitu .405

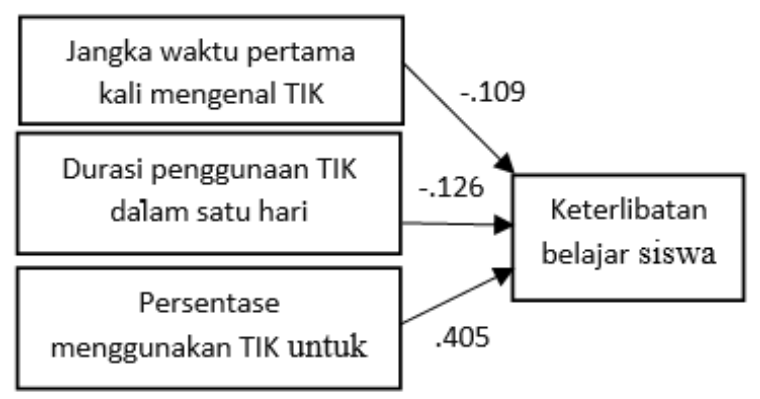

\section{Gambar 1. Diagram korelasi indikator intensitas penggunaan TIK terhadap keterlibatan belajar siswa.}

Selain itu, juga ditemukan bahwa jangka waktu pertama kali mengenal TIK berkorelasi signifikan secara positif terhadap durasi penggunaan TIK dalam satu hari, dan berkorelasi negatif dengan persentase penggunaan TIK yang ditujukan untuk kepentingan akademis. Durasi penggunaan 
TIK dalam satu hari juga berkorelasi negatif dengan persentase penggunaan TIK untuk kepentingan akademis.

\section{Pembahasan}

Hubungan antara jangka waktu pertama kali menggunakan TIK dengan keterlibatan belajar

Berdasarkan hasil uji korelasi yang dilakukan, diperoleh bahwa jangka waktu pertama kali menggunakan TIK pada responden berkorelasi negatif terhadap keterlibatan belajar siswa, hal ini menunjukkan bahwa semakin cepat mahasiswa mengenal dan menggunakan TIK maka akan semakin rendah pula keterlibatan belajarnya.

Sejalan dengan data temuan survei mengenai penetrasi dan profil perilaku pengguna internet Indonesia pada tahun 2018 yang dilakukan oleh Asosiasi Penyelenggara Jasa Internet Indonesia (APJII) bahwa mayoritas pengguna teknologi informasi dan komunikasi adalah remaja yang berusia 1519 tahun yaitu generasi $Z$ dalam penelitian ini. APJII juga menyebutkan bahwa mayoritas penduduk Indonesia telah menggunakan internet lebih dari 7 atau 8 tahun sebelumnya, sesuai dengan penemuan dalam penelitian ini dimana mahasiswa di Fakultas Psikologi, Universitas $X$ yang menjadi partisipan ratarata menggunakan teknologi informasi dan komunikasi sejak 9 tahun yang lalu.

Hubungan antara durasi penggunaan TIK dengan keterlibatan belajar

Penelitian ini juga menemukan bahwa durasi penggunaan TIK dalam satu hari berkorelasi negatif terhadap keterlibatan belajar siswa, hal ini berarti semakin lama seorang mahasiswa menggunakan TIK dalam satu hari maka semakin rendah pula keterlibatan belajarnya.

Tabel 2. Tabel perbandingan korelasi antar indikator intensitas penggunaan TIK terhadap keterlibatan belajar mahasiswa. ${ }^{* *} \mathrm{p}<0.01$.

\begin{tabular}{|c|c|c|c|c|}
\hline & $\begin{array}{l}\text { Jangka waktu } \\
\text { pertama kali } \\
\text { mengenal TIK }\end{array}$ & $\begin{array}{l}\text { Durasi } \\
\text { penggunaan TIK } \\
\text { dalam satu hari }\end{array}$ & $\begin{array}{l}\text { Persentase } \\
\text { penggunaan TIK untuk } \\
\text { kepentingan akademis }\end{array}$ & $\begin{array}{l}\text { Keterlibatan } \\
\text { belajar siswa }\end{array}$ \\
\hline $\begin{array}{l}\text { Jangka waktu pertama } \\
\text { kali mengenal TIK }\end{array}$ & & $.212^{*}$ & -.060 & -.109 \\
\hline $\begin{array}{l}\text { Durasi penggunaan TIK } \\
\text { dalam satu hari }\end{array}$ & & & -.064 & -.126 \\
\hline $\begin{array}{l}\text { Persentase } \\
\text { penggunaan TIK untuk } \\
\text { kepentingan akademis }\end{array}$ & & & & $.405^{* *}$ \\
\hline
\end{tabular}

Penelitian sebelumnya pada pembelajar tingkat perguruan tinggi yang pernah dilakukan oleh Derbyshire et al., (2013) pada 2108 mahasiswa menunjukkan hasil yang sama. Penelitian tersebut menemukan bahwa semakin sering mahasiswa menggunakan internet maka semakin rendah nilai ratarata akademis, semakin jarang berolahraga, semakin tinggi skor terhadap tes gejala depresi dan semakin tinggi juga skor tes stress mereka.
Hasil ini juga menunjukkan kesesuaian dengan survei mengenai penetrasi penggunaan internet di Indonesia yang menunjukkan rata-rata penggunaan internet penduduk di Indonesia mayoritas adalah lebih dari 4 jam dalam sehari. Berkaitan dengan korelasinya yang juga negatif dengan keterlibatan belajar, menjadi indikator yang cukup jelas dikarenakan tujuan mayoritas penduduk Indonesia menggunakan internet, terutama para generasi $\mathrm{Z}$ bukanlah untuk 
kepentingan proses pembelajaran dalam perkuliahan, melainkan untuk mengakses sosial media dan berkirim pesan (Asosiasi Penyelenggara Jasa Internet Indonesia, 2018).

Data terbaru dari Hootsuite (Kemp, 2020), juga menyebutkan bahwa penduduk Indonesia banyak mengakses internet via telepon genggam dan sebesar $96 \%$ mengakses internet untuk kepentingan berkirim pesan dan sosial media.

\section{Hubungan antara persentase penggunaan TIK untuk kepentingan akademis dengan keterlibatan belajar}

Namun, hasil yang berbeda ditemukan pada indikator persentase penggunaan TIK dalam satu hari untuk kepentingan akademis. Dari hasil ditemukan bahwa ketika seseorang menggunakan TIK untuk kepentingan akademis maka berkorelasi positif secara signifikan terhadap keterlibatan belajar siswa, yang berarti bahwa ketika seseorang semakin banyak menggunakan TIK untuk kepentingan akademis, maka akan semakin tinggi pula keterlibatan belajar siswanya.

Berdasarkan pemaparan analisis di atas, maka hasil yang diperoleh dalam penelitian ini turut mendukung temuan pada penelitian sebelumnya yang menyebutkan bahwa dengan penggunaan TIK dalam proses belajar dan mengajar maka akan memberikan dampak pada pembelajaran seseorang (Beetham \& Sharpe, 2013; Losh, 2014).

Terdapat beberapa penelitian terdahulu yang juga telah mengkonfirmasi bahwa penggunaan TIK dalam lingkungan akademis dapat memberikan dampak yang positif baik bagi pengajar maupun kepada siswanya. Seperti yang dikemukakan Sun et al. (2016) dalam penelitiannya menemukan bahwa ketika siswa mempersepsi atribut dari teknologi sebagai sesuatu yang menarik minat dan menguntungkan bagi mereka, mereka akan memanfaatkan teknologi tersebut sebaik mungkin. Pemanfaatan teknologi ini, mereka tunjukkan untuk semakin meningkatkan pemahaman mengenai materi pembelajaran yang sedang berlangsung.

Secara umum, dengan keberadaan teknologi dalam dunia pendidikan, pembelajar semakin merasa perlu melibatkan diri untuk terus mengembangkan pengetahuan dan pemahaman terhadap materi ajar karena berbagai informasi dapat dengan mudah diperoleh darimana saja dan kapan saja (Miller, Milholland \& Gould, 2012).

Selain itu, pembelajar juga meyakini bahwa fasilitas kemudahan mengakses TIK pada zaman sekarang ini memberi manfaat bagi mereka untuk dapat mempelajari materi pembelajaran dengan lebih baik, mendorong prestasi akademik, dan lebih mempersiapkan mereka untuk terjun dalam lingkungan pekerjaan yang berbasis teknologi (Schindler, Burkholder, Morad \& Marsh, 2017).

Dari sini, ditemukan indikasi bahwa generasi $Z$ yang merupakan mahasiswa jenjang S1 di Fakultas Psikologi, Universitas $\mathrm{X}$, masih membutuhkan pengarahan dan panduan dalam menggunakan teknologi informasi dan komunikasi untuk keperluan belajar dan mengajar. Seperti yang diutarakan oleh Patrikakou (2016), bahwa dengan panduan orang tua maka penggunaan TIK akan lebih efektif dan efisien, sehingga semakin memberikan manfaat yang baik bagi penggunanya, dalam hal ini generasi $Z$.

Penemuan yang juga sangat menarik dikemukakan oleh Chen \& Jang, (2010) dan Giesbers et al. (2013). Dalam penelitian -penelitian tersebut dijelaskan bahwa yang perlu menjadi perhatian bukanlah TIK itu sendiri melainkan lebih kepada bagaimana penggunaan TIK tersebut agar dapat bermanfaat dalam dunia akademis.

Chen dan Jang (2010) menjelaskan bahwa motivasi dalam menggunakan TIK dalam kepentingan belajar memerankan peranan penting berkaitan dengan proses pembelajaran yang berlangsung.

Penelitian yang dilakukan oleh Giesbers et al (2013) menemukan bahwa motivasi intrinsik yang terdapat pada diri pembelajar menjadi prediktor yang kuat terhadap keterlibatan perilaku dari pembelajar. Selain itu, keterlibatan perilaku berupa partisipasi dalam pembelajaran merupakan prediktor paling kuat yang menentukan prestasi akademis dalam penelitiannya.

Beberapa penelitian bahkan menekankan pada fenomena yang banyak terjadi bahwa ketika TIK hadir dalam lingkungan akademis, 
praktik pengajaran yang dilakukan oleh pengajar tetap bersifat tradisional dan tidak mengaplikasikan strategi pedagogis yang lebih sesuai sehingga kemudian justru dengan adanya TIK semakin memperburuk prestasi akademis (Chen \& Jang, 2010; HåkanssonLindqvist, 2015).

Dalam institusi pendidikan, pemanfaatan teknologi informasi dan komunikasi dalam kegiatan belajar mengajar sudah banyak digunakan baik dalam ruang kelas maupun di luar kelas. TIK terutama internet, bahkan telah menjadi sumber informasi yang dan pengetahuan baru bagi mahasiswa S1 Fakultas Psikologi Universitas $\mathrm{X}$ berdasarkan wawancara awal yang dilakukan oleh peneliti. Namun, berdasarkan hasil empiris dari penelitian, dengan masih banyak mahasiswa yang tidak menggunakan teknologi informasi dan komunikasi dengan efektif untuk kepentingan akademis mereka, menunjukkan bahwa para mahasiswa yang termasuk generasi $Z$ ini masih membutuhkan panduan dan batasan dari pengajar dalam pemanfaatan teknologi informasi dan komunikasi yang mereka miliki.

Grissom et al. (2017) mengungkapkan bahwa pengajar memiliki peranan penting agar TIK dapat dimanfaatkan dengan baik oleh para pembelajar untuk pembelajaran mereka. Dalam penelitiannya, ia menemukan bahwa pengajar yang tetap mempertahankan cara tradisional dalam mengajar seperti berpusat kepada guru dan tidak mendorong interaksi antar siswa dan interaksi lebih siswa dengan materi ajar membuat prestasi akademik mereka semakin menurun.

Selain itu, penelitian yang dilakukan oleh Harnish et al., (2018) juga menemukan bahwa institusi pendidikan perlu memanfaatkan berbagai penggunaan teknologi informasi dan komunikasi di dalam kelas, namun guru dan administrator perlu memilih perangkat yang tepat dan selalu memberikan panduan yang jelas kepada para siswa yang memanfaatkannya.

\section{SIMPULAN}

Berdasarkan hasil penelitian, ditemukan bahwa intensitas penggunaan teknologi informasi dan komunikasi (TIK) memiliki korelasi terhadap keterlibatan belajar para mahasiswa. Dua dimensi dari intensitas penggunaan TIK yaitu jangka waktu pertama kali mengenali TIK dan durasi penggunaan berkorelasi negatif terhadap keterlibatan belajar. Sedangkan untuk dimensi persentase penggunaan TIK untuk kepentingan akademik berkorelasi positif. Dari penelitian ini, maka mahasiswa generasi $Z$ sebaiknya menentukan sejak awal tujuan pemanfaatan TIK dalam belajar, dan memiliki regulasi diri dalam belajar yang baik. Selain itu juga, penting bagi institusi pendidikan dan pengajar agar terus memberikan arahan dan himbauan dalam penggunaan teknologi dan informasi agar senantiasa mengakses informasi yang berkaitan dengan akademik agar keterlibatan belajar mereka juga semakin baik. Pengajar juga dapat memodifikasi penggunaan TIK, misal dengan memanfaatkan berbagai aplikasi berbasis internet seperti konferensi via internet, zoom meeting, aplikasi kuis berbasis daring, sosial media berupa video pembelajaran seperti Youtube untuk meningkatkan relevansi pembelajaran dengan gaya hidup generasi $Z$ yang dekat dengan TIK agar semakin meningkatkan keterlibatan belajar mereka dalam perkuliahan.

Saran untuk penelitian selanjutnya, agar dapat memperoleh jumlah sampel yang lebih banyak dengan variasi jenjang pendidikan, institusi pendidikan dan kota yang ada di Indonesia untuk memperoleh hasil yang komprehensif dan mewakili mengenai generasi $Z$ di Indonesia. Selain itu, mengingat penggunaan TIK telah umum dalam pendidikan maka pada penelitian selanjutnya dapat juga diteliti mengenai orientasi tujuan belajar, literasi digital dan prestasi akademik dari para pembelajar dalam konteks pembelajaran digital. Dengan meneliti konstruksi-konstruksi ini, maka akan dapat diperoleh pemahaman yang lebih mendalam mengenai dinamika pengaruh penggunaan TIK dalam dunia pendidikan.

\section{DAFTAR PUSTAKA}

Asosiasi Penyelenggara Jasa Internet Indonesia. (2018). Survei Nasional Penetrasi Pengguna Internet 2018. Jakarta. 
Anderson, B., Fagan, P., Woodnutt, T., \& Chamorro-Premuzic, T. (2012). Facebook psychology: Popular questions answered by research. Psychology of Popular Media Culture, 1, 23-37.

Beetham, Helen \& Sharpe, Rhona. (2013). Rethinking pedagogy for a digital age: Designing for 21st Century Learning. USA: Routledge.

Awan, M.A. \& Khan, H.U. (2016) Status of internet addiction among college students: a case of South Korea, first american academic research conference on global business, economics, finance and social sciences, New York, USA.

Chen, K.-C., \& Jang, S.-J. (2010). Motivation in online learning: Testing a model of selfdetermination theory. Computers in Human Behavior, 26, 741-752. http:// doi.org/10.1016/j.chb.2010.01.011

Christenson, S. L. (2013). Handbook of research on student engagement. Springer.

Cole, K. (2019, July 8). 6 Tech Tools for Enhancing Communication In the Classroom (and Out). https://www.schoology. com/blog/6-tech-tools-enhancingcommunication-classroom-and-out.

Derbyshire, K. L., Lust, K. A., Schreiber, L. R., Odlaug, B. L., Christenson, G. A., Golden, D. J., \& Grant, J. E. (2013). Problematic internet use and associated risks in a college sample. Elsevier Journal of Comprehensive Psychiatry, 54(5), 415422.

Dogan, U. (2015). Student Engagement, Academic Self-efficacy, and Academic Motivation as Predictors of Academic Performance. The Anthropologist, 20(3), 553-561. https://doi.org/10.108 0/09720073.2015.11891759

Drain, T., Grier, L., \& Sun, W. (2012). Is the growing use of electronic devices beneficial to academic performance? Results from archival data and a survey. Issues in Information Systems, 13(1).

Giesbers, B., Rienties, B., Tempelaar, D., \& Gijselaers, W. (2013). Investigating the relations between motivation, tool use, participation, and performance in an e-learning course using webvideoconferencing. Computers in Human
Behavior, 29(1), 285-292. http://doi. org/10.1016/j.chb.2012.09.005

Gliner, J. A., \& Morgan, G. A. (2000). Research methods in applied settings: An integrated approach to design and analysis. Lawrence Erlbaum Associates Publishers.

Fonseca, D.; Martí, N.; Redondo, E.; Navarro, I.; Riera, A. (2014). Relationship between student profile, tool use, participation, and academic performance with the use of Augmented Reality technology for visualized architecture models. Computers in Human Behavior. 31. 434445. 10.1016/j.chb.2013.03.006.

Francis, T., \& Hoefel, F. (2018). True Gen: Generation $Z$ and its implications for companies. McKinsey \& Company. https://www.mckinsey.com/industries/ consumer-packaged-goods/ourinsights/true-gen-generation-z-and-itsimplications-for-companies.

Fredricks, J. A., Blumenfeld, P. C., \& Paris, A. (2004). School engagement: Potential of the concept: State of the evidence. Review of Educational Research, 74, 59119. doi: 10.3102/00346543074001059

Fredricks, J. (2013). Behavioral engagement in learning. In J. Hattie \& E. M. Anderman (Eds.), Educational psychology handbook series. International guide to student achievement (p. 42-44). Routledge/Taylor \& Francis Group.

Grissom, S., McCauley, R., \& Murphy, L. (2017). How Student Centered is the Computer Science Classroom? A Survey of College Faculty. ACM Transactions on Computing Education, 18(1), 1-27. http://doi.org/10.1145/3143200

Gulek, James \& Demirtas, Hakan. (2004). Learning With Technology: The Impact of Laptop Use on Student Achievement. Journal of Technology, Learning, and Assessment. 3.

Håkansson Lindqvist, M. (2015). Conditions for Technology Enhanced Learning and Educational Change : a case study of a 1:1 initiative (PhD dissertation). Umeå universitet, Umeå. Retrieved from http://urn.kb.se/resolve?urn=urn:nbn:s e:umu:diva-109887 
Harnish, R. J., Bridges, K. R., Sattler, D. N., Signorella, M. L., \& Munson, M. (Eds.). (2018). The Use of Technology in Teaching and Learning. Retrieved from the Society for the Teaching of Psychology web site: http://teachpsych.org/ebooks/

Hart, S. R., Stewart, K., \& Jimerson, S. R. (2011). The Student Engagement in Schools Questionnaire (SESQ) and the Teacher Engagement Report Form-New (TERF-N): Examining the Preliminary Evidence. Contemporary School Psychology, 15(1), 67-79. Retrieved from http://www.casponline.org/pdfs/ pdfs/2011_journal_all_001-144-b. pdf\#page $=69$.

Hughes, K. (2015). Impact of Student Engagement on Achievement and WellBeing. 10.13140/RG.2.1.2536.3684.

Jacobsen, W. C., \& Forste, R. (2011). The wired generation: academic and social outcomes of electronic media use among university students. Cyberpsychology, Behavior, and Social Networking, 14(5). http://dx.doi. org/10.1089/cyber.2010.0135.

Kemp, S. (2020, February 18). Digital 2020: Indonesia - DataReportal - Global Digital Insights. DataReportal. https:// datareportal.com/reports/digital-2020indonesia.

Losh, E. (2014). The war on learning: Gaining ground in the digital university. USA: MIT Press.

MacKenzie, J., \& McGuire, R. (2016). The First Generation of the Twenty-First Century. Retrieved November 8, 2016, from http:// magid.com/sites/default/files/pdf/ MagidPluralistGenerationWhitepaper.pdf

Miller, J. P., Milholland, E. S., \& Gould, S. M. (2012). Determining the attitudes of students toward the use of a classroom response in hospitality courses. Journal of Hospitality \& Tourism Education, 24(2-3), 73-79.

Oblinger, D. G., \& Oblinger, J. L. (2005). Educating the Net Generation. Washington, DC: Educause. From www. educause.edu/educatingthenetgen.

Patrikakou, E. (2016). Parent involvement, technology, and media: now what?
School Community Journal. 26(2).

Saeed, S., \& Zyngier, D. (2012). How Motivation Influences Student Engagement: A Qualitative Case Study. Journal of Education and Learning, 1(2). https:// doi.org/10.5539/jel.v1n2p252

Sana, F., Weston, T., \& Cepeda, N. J. (2013). Laptop multitasking hinders classroom learning for both users and nearby peers. Computers \& Education, 62. http://dx.doi.org/10.1016/j. compedu.2012.10.003.

Schindler, L. A., Burkholder, G. J., Morad, O. A., \& Marsh, C. (2017). Computer-based technology and student engagement: a critical review of the literature. International Journal of Educational Technology in Higher Education, 14(1), 25.

Suhail, K., \& Bargees, Z. (2006). Effects of excessive Internet use on undergraduate students in Pakistan. Cyber Psychology \& Behavior, 9(3), 297e307. http:// dx.doi.org/10.1089/cpb.2006.9.297.

Sun, S., Lee, P., Lee, A., \& Law, R. (2016). Perception of attributes and readiness for educational technology: Hospitality management students' perspectives. Journal of Hospitality \& Tourism Education, 28(3), 142-154.

Trimmel, M., \& Bachmann, J. (2004). Cognitive, social, motivational and health aspects of students in laptop classrooms. Journal of Computer Assisted Learning, 20. http://dx.doi.org/10.1111/j.13652729.2004.00076.x.

Turner, A. (2015). Generation Z: Technology and Social Interest. The Journal of Individual Psychology, 71(2), 103-113. doi:10.1353/jip.2015.0021.

Voelkl, K. E. (2012). School Identification. In S. Christenson, A. Reschly, \& C. Wylie (Eds.) Handbook of Research on Student Engagement (pp. 193-218). New York: Springer.

Wiedmer, T. (2015). Generation Do Differ: Best Practices in Leading Traditionalists, Boomers and Generations $X, Y$ and Z. The Delta Kappa Gamma Bulletin: International Journal for Professional Educators, 51-58. 